\title{
Chronic sacroiliac joint pain in elderly treated with pulsed radiofrequency ablation
}

\section{Farid Yudoyono 1,2 \\ Dewi Pratiwi' \\ Hendra Gunawan' \\ Deasy Herminawaty'}

'Neurospine and Pain Center, Santosa Hospital Bandung Kopo, Bandung, Jawa Barat, Indonesia

${ }^{2}$ Departement of Neurosurgery, Hasan Sadikin Hosptal, College of Medicine, Universitas Padjadjaran, Bandung, Jawa Barat, Indonesia

\section{Cite this article}

Yudoyono F, Pratiwi D, Gunawan H, Herminawaty D. Chronic sacroiliac joint pain in elderly treated with pulsed radiofrequency ablation. Neurologico Spinale Medico Chirurgico. 2020;3(I): 9-II. DOI: I 0.36444/nsmc.v3il.3

Corresponding author:

Farid Yudoyono

Departement of Neurosurgery,

Hasan Sadikin Hospital, College of Medicine,

Universitas Padjadjaran, Bandung,

Jawa Barat, Indonesia

E-mail: faridspine@gmail.com

\begin{abstract}
Chronic sacroiliac joint (SI) pain can cause disability in an aging society. Effective treatment of low back pain (LBP) originating from sacroiliac joints is difficult to achieve. We report the successful treatment of pulsed radiofrequency (PRF) ablation in a patient with chronic SI joint pain. There were no post-interventional complications. Clinical improvement reported after 12 months.
\end{abstract}

Keywords: ablation, chronic pain, radiofrequency, sacroiliac joint.

\section{Introduction}

Chronic low back pain is a major cause of disability in the United States. An average of $15-20 \%$ lower back pain originates from the sacroiliac joint. ${ }^{1-6}$ This sacroiliac joint supports the unique curve-shaped diarthrodial joint, receiving innervation from the lumbosacral plexus. Neuro-physiologically, several studies have demonstrated that there are nociceptive and proprioceptive afferent nerves in the sacroiliac joint. ${ }^{1,3,7,8}$

There are some ambiguities and difficulties that occur when evaluating and determining the right diagnosis and appropriate setting for therapeutic management. Patients are more likely to experience sacroiliitis and intervention therapy is very rare. ${ }^{9}$ Currently, there is an exponential development in the management of pain originating from the sacroiliac joint.

Pulsed Radiofrequency (PRF) ablation is one of the management options for chronic pain and refractory pain for sacroiliac joint pain. ${ }^{4}$ There are some variety of therapies including denervation, intraarticular injection using local anesthesia, corticosteroids, and surgery but none has been effective in reducing pain within longterm period. ${ }^{10}$

International Association for the Study of Pain diagnostic criteria for sacroiliac syndrome include: pain in the region of the sacroiliac joint with possible radiation to the groin, medial buttocks, and posterior thigh; reproduction of pain by physical examination techniques that stress the joint. ${ }^{2}$

\section{Case Presentation}

Patients are selected based on the criteria of persistent chronic pain from the sacroiliac joint, no respond with conservative therapy. Previously, all patients who had clinical suspicion of SI joint pain underwent diagnostic SI joint injections. Those with $>50 \%$ pain relief from diagnostic injections were offered RFA. As with traditional RFA techniques, the patient is placed in the prone position under fluoroscopic guidance, the probe is inserted through the skin to contact the bony margin lateral to the S4 foramen (Figure 1 and 2). We followed the protocol, wherein each 
lesion is created uses radiofrequency current with short, high-voltage, the silent phase allows time for heat elimination, and generally keeping the tissue target below $42^{\circ} \mathrm{C}$ for 120 seconds. ${ }^{11-13}$

\section{Case I}

A 57-year-old woman presented with a 3-year history of the predominant buttock and low back pain for more than six months. The pain started in the right buttock VAS 7 and was intermittently worse. Signs and symptoms of sacroiliac joint pain on physical examination; failure to achieve adequate pain relief with physical therapy or pharmacotherapy. The author using Magnetic resonance imaging (MRI) as diagnostic and demonstrated large subcortical erosions on both the sacral and iliac sides with bone marrow edema at the sacral side of the right SI joint. We performed the right SI joint PRF Ablation (Figure 1). VAS 2 achieved within 12 months after the procedure.

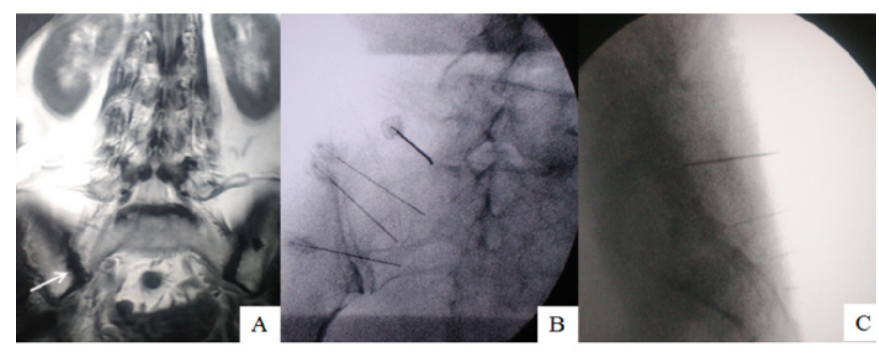

Figure 1. A) MRI T2WI coronal view showed grade III subchondral sclerosis (white arrow). B) Real-time anterior view fluoroscopy RFA. C) Lateral view fluoroscopy.

\section{Case II}

An 82-year-old woman presented with a 4-year history of refractory low back and buttock pain with VAS 7. The pain started in the right low back and intermittently worsen. Signs and symptoms of sacroiliac joint pain on physical examination; failure to achieve adequate pain relief with physical therapy or pharmacotherapy. The plain X-ray showed subcortical erosions and sclerosis at the SI joint. Magnetic resonance imaging (MRI) of the SI joint demonstrated subcortical erosions with bone marrow edema at the right SI joint. We performed the right SI joint PRF Ablation (Figure 2). VAS 2 achieved within 12 months after the procedure.

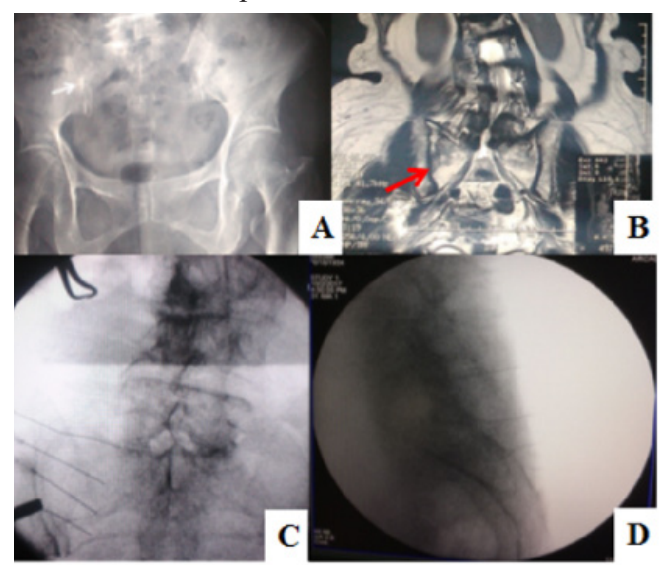

Figure 2. A) Plain X-ray showed sclerosis on the bilateral SI joint (white arrow). B) MRI T2WI coronal view showed subchondral sclerosis (red arrow). C) Real-time anterior fluoroscopy RFA. D) Lateral view fluoroscopy.

\section{Discussion}

Various literature mentions many treatment methods for dealing with low back pain originating from SI joints. Interventional treatments include sacroiliac joint, intra-articular joint injections, cryotherapy, and surgical treatment. Although all of these methods, pain relief is a challenger in many cases. ${ }^{1,2,5}$ Previous study reported that pulsed radiofrequency denervation of the L4 and L5 primary dorsal rami and S1-3 lateral branches provide significant pain relief and functional improvement compared to intra-articular injection. ${ }^{14}$

$\mathrm{RF}$ ablation in the sacroiliac joint is an action carried out based on the result of previous cadaver studies stating that there are anastomosed nerves with multiple dorsal primary branches around the neural foramen. ${ }^{6}$

The sacroiliac joint continues to be a source of chronic lower back pain even though there is still debate of pain source and its anatomical property. The innervation of the dorsal area of the sacroiliac joint (SI) has been widely reported based on the result of previous studies originating from L4 and L5 dorsal ramus and nerve S1,2,3 and a small portion of S4..$^{1-5}$

In this study, the authors prove that PRF ablation performed on the sacroiliac joints decreases $>50 \%$ of pain scale and is followed by a reduction in the dose of analgesic in patients experiencing sacroiliac joint pain. This result was similar with previous studies. ${ }^{3,15}$

PRF ablation has shown to be clinically effective in the management of SI joint pain but in this study also showed that in 9 months after procedure there was $<50 \%$ reduction of the pain scale, this is due to the diffuse innervation of the SIJ extending from the L5 to S4 and large of subcortical bony erosion. ${ }^{6}$ The author gives additional non-steroid anti-inflammation drug.

One patient complaint sensation of pain and heat over the skin of the trajectory site post-PRF ablation. Hegarty et al. ${ }^{16}$ reported that the symptoms will decrease gradually by $60 \%$ within 7 -months. The complaint had minimal effect for most patients requires no intervention. ${ }^{16}$ In our cases, this complaint reduced by analgesic.

Our results are unique because occurred in elderly with unilateral symptom and demonstrated the long-term efficacy of sacroiliac joint pain management. No serious complications or side effects were observed in our patients. Both patients showed a clinically relevant degree of pain relief.

But there are some limitations in the management of SI joint pain, extensive neurons and inconsistency of the technique used for RFA in SI joints. More extensive studies with large samples and longer observation times are needed. ${ }^{16}$

\section{Conclusion}

PRF ablation provides high and longer clinical effectiveness in chronic SI joint pain management in elderly patients who have been properly screened. 


\section{Acknowledgement}

There is no potential conflict of interest relevant to this article reported. No specific grant was provided for this article. All authors took part in the design of the study, literature review, and writing the manuscript.

\section{References}

1. Cosman ER, Gonzalez CD. Bipolar radiofrequency lesion geometry: implications for palisade treatment of sacroiliac joint pain. Pain Practice. 2011;11(1):3-22. DOI: 10.1111/j.15332500.2010.00400.x

2. Romero FR, Vital RB, Zanini MA, et al. Long-term follow-up in sacroiliac joint pain patients treated with radiofrequency ablative therapy. Arq Neuropsiquiatr. 2015;73(6):476-79. DOI: 10.1590/0004-282X20150049

3. Cox RC, Fortin JD. The anatomy of the lateral branches of the sacral dorsal rami: implications for radiofrequency ablation. Pain Physician. 2014;17:459-64.

4. Cheng J, Chen SL, Zimmerman N, et al. A new radiofrequency ablation procedure to treat sacroiliac joint pain. Pain Physician. 2016;19:603-15.

5. Biswas BK, Dey S, Biswas S, et al. Water-cooled radiofrequency neuroablation for sacroiliac joint dysfunctional pain. Journal of Anaesthesiology Clinical Pharmacology. 2016;32(4):525-27. DOI: 10.4103/0970-9185.168261

6. Choi WS, Kim JS, Ryu KS, et al. Endoscopic Radiofrequency ablation of the sacroiliac joint complex in the treatment of chronic low back pain: A preliminary study of feasibility and efficacy of a novel technique. BioMed Research International. 2016;2016:2834259. DOI: 10.1155/2016/2834259

7. Rupert MP, Lee M, Manchikanti L, et al. Evaluation of sacroiliac joint interventions: A systematic appraisal of the literature. Pain Physician. 2009;12:399-418.
8. Zacchino M, Almolla J, Canepari E, et al. Use of ultrasoundmagnetic resonance image fusion to guide sacroiliac joint injections: a preliminary assessment. J Ultrasound. 2013;16:111-18. DOI: $10.1007 / \mathrm{s} 40477-013-0028-7$

9. Hansen H, Manchikanti L, Simopoulos TT, et al. A systematic evaluation of the therapeutic effectiveness of sacroiliac joint interventions. Pain Physician. 2012;15:E247-78.

10. Ho KY, Hadi MA, Pasutharnchat K, et al. Cooled radiofrequency denervation for treatment of sacroiliac joint pain: two-year results from 20 cases. Journal of Pain Research. 2013;6:505-11. DOI: $10.2147 /$ JPR.S46827

11. Cheng J, Chen SL, Zimmerman N, et al. A new radiofrequency ablation procedure to treat sacroiliac joint pain. Pain Physician. 2016;19:603-15.

12. Schmidt PC, Pino CA, Vorenkamp KE. Sacroiliac joint radiofrequency ablation with a multilesion probe: A case series of 60 patients. Anesthesia \& Analgesia. 2014;119(2):460-62. DOI: 10.1213/ANE.0000000000000282

13. Byrd D, Mackey S. Pulsed radiofrequency for chronic pain. Curr Pain Headache Rep. 2008;12(1):37-41. DOI: 10.1007/ s11916-008-0008-3

14. Dutta K, Dey S, Bhattacharyya P, et al. Comparison of efficacy of lateral branch pulsed radiofrequency denervation and intraarticular depot methylprednisolone injection for sacroiliac joint pain. Pain Physician. 2018;21(5):489-96.

15. Salman OH, Gad GS, Mohamed AA, et al. Randomized, controlled blind study comparing sacroiliac intra-articular steroid injection to radiofrequency denervation for sacroiliac joint pain. Egyptian Journal of Anaesthesia. 2016;32:219-25. DOI: 10.1016/j.egja.2015.07.005

16. Hegarty D. Clinical outcome following radiofrequency denervation for refractory sacroiliac joint dysfunction using the simplicity iii probe: A 12-month retrospective evaluation. Pain Physician. 2016;19:E129-35. 